\title{
Variability of pterygoid teeth in three species of Podarcis lizards and the utility of palatal dentition in lizard systematics
}

\author{
Tomasz Skawiński $^{1, *}$, Bartosz Borczyk $^{1}$ \& Edyta Turniak ${ }^{1}$ \\ ${ }^{1}$ Department of Evolutionary Biology and Conservation of Vertebrates, \\ Faculty of Biological Sciences, University of Wrocław, Wrocław, Poland. \\ *Corresponding author: tomasz.skawinski@uwr.edu.pl
}

\begin{abstract}
Palatal dentition in lizards is incompletely known, especially data on its variability are scarce. We studied variation in the number of pterygoid teeth in three species of Podarcis, a species-rich genus of lacertid lizards: terrestrial, $P$. siculus and saxicolous, $P$. erhardii and $P$. cretensis. In contrast to some previous studies, we found no sexual dimorphism in the number of palatal teeth in any of these species. The number of teeth was not correlated to lizard size. In our sample, $P$. cretensis on average had more teeth than did $P$. erhardii but fewer than did $P$. siculus. In addition, some specimens of $P$. cretensis and $P$. siculus showed asymmetry in the number of pterygoid teeth, which may be a result of anthropogenic pressure. The observed variability in the occurrence of palatal dentition illustrates the importance of scoring this character in phylogenetic analyses only on the basis of a sufficient sample.
\end{abstract}

KEYWORDS. Heterochrony, paedomorphosis, peramorphosis, cryptic species, morphology.

Skawiński T., Borczyk B. \& Turniak E. 2017. Variability of pterygoid teeth in three species of Podarcis lizards and the utility of palatal dentition in lizard systematics. Belgian Journal of Zoology 147 (2): 129-135. https://doi.org/10.26496/bjz.2017.10

\section{Introduction}

Palatal dentition occurs frequently in squamate reptiles - it is present in at least some members of most family-level lizard clades, but is relatively poorly known when compared to marginal dentition. In lizards, teeth may be present on palatine, vomer and, most commonly, pterygoid bones. In lacertids, a large group of Old World lizards, the only tooth-bearing palatal bones are the pterygoids (MAHLER \& KEARNEY 2006). However, many members of that clade (such as Zootoca vivipara, Algyroides marchi, Iberolacerta spp. and some species of Podarcis) have no pterygoid teeth (e.g., BARAHONA \& BARBADILLO 1997), while in many others (such as Algyroides moreoticus, A. nigropunctatus and some other Podarcis species) this trait shows intraspecific variation (MAHLER \& KEARNEY 2006).

In lacertid ontogeny, palatal dentition develops later than do marginal teeth (BARAHONA \& BARBADILLO 1998). Generally, pterygoid teeth are regarded as a trait occurring in large lacertids (e.g., ARNOLD 1989; BARAHONA \& BARBADILlO 1998; COSTANTINI et al. 2010) and in taxa with robust skulls (ARNOLD et al. 2007). This robustness is probably a result of peramorphosis, as is a sexual dimorphism in these lizards (PIRAS et al. 2011). Thus, presence of a well-developed palatal dentition should be expected especially in larger species and in males. Podarcis is a diverse genus of lacertid lizards that includes over 20 species with different morphologies (slender and robust) and different ecologies such as saxicolous or terrestrial 
(e.g., ARNOLD et al. 2007). Pterygoid dentition in Podarcis lizards has been described by several authors (e.g., KLEMMER 1957; ARNOLD 1973; BARAHONA \& BARBADILlO 1997), but quantitative data on its variability are mostly lacking or based on very limited samples for many species (MAHLER \& KEARNEY 2006; COSTANTINI et al. 2010). Therefore, any conclusions about relative frequency of pterygoid teeth among Podarcis lizards must be regarded as tentative.

Our aim was to assess the variability of pterygoid teeth in several species of Podarcis lizards and the utility of this character in lizard systematics. We also tested expectations about greater frequency of the palatal dentition in larger species and in males.

\section{Material and methods}

Presence and number of pterygoid teeth were recorded from a total of 41 specimens from three species of lizards of the genus Podarcis: P. siculus $(\mathrm{n}=21)$, P. erhardii $(\mathrm{n}=10)$ and P. cretensis $(\mathrm{n}=10)$. Podarcis siculus is a large, terrestrial species while P. erhardii and $P$. cretensis are somewhat smaller and are more saxicolous (ARNOLD et al. 2007). To our knowledge, palatal dentition has not previously been described in P. cretensis. Specimens of P. siculus are deposited in the Museum of Natural History, University of Wrocław, and were obtained from the Wrocław Zoo in the 1930s (unfortunately, labels indicating place of their origin were destroyed during World War II). Specimens of $P$. erhardii and $P$. cretensis were obtained from the Natural History Museum of Crete. The former were collected at the Santorini island in the Cyclades and the latter at the island of Elafonisos near Crete. Snout-vent length (SVL) of each specimen was measured to the nearest millimetre (Table 1). The sample size may seem low, but in osteological studies of lizards the most common number of examined specimens is one (BELL \& MEAD 2014). Potential differences between sexes and species in number of pterygoid teeth (on both bones) were analysed using Mann-Whitney U-test $(U)$ and potential correlation between size (i.e., SVL) and number of palatal teeth using Pearson correlation (r). One specimen of $P$. siculus with one pterygoid missing was excluded from the tests. All analyses were performed in IBM SPSS Statistics 20.

Podarcis siculus and P. erhardii are lizards widespread in the Mediterranean, the former especially in Italy and coastal parts of the Western Balkans, the latter in the South-Eastern Balkans and many Aegean islands. Podarcis cretensis is an endangered species endemic to Crete and its satellite islands. Until recently it was regarded as conspecific with P. erhardii (LYMBERAKIS et al. 2008).

\section{Results}

In the examined specimens of $P$. siculus palatal teeth were common, occurring in 17 of 21 specimens $(80.95 \%)$; they were present in five of six females (83.33\%), at about the same frequency as in males (12 of $15 ; 80 \%$ ). Moreover, quite commonly smaller individuals had more teeth than did the larger ones (Table 1). Teeth on at least one of the pterygoids were present in all specimens of $P$. cretensis, including the smallest lizard in the sample ( $\mathrm{SVL}=46 \mathrm{~mm}$ ), while they were very rare in $P$. erhardii, being present in only one specimen (the largest male).

In all examined specimens the pterygoid teeth were small, monocuspid and arranged more or less in a single, longitudinal row.

Asymmetry in number of pterygoid teeth, i.e., difference in number of teeth on left and right pterygoid, was present in eleven specimens of P. siculus $(55 \%$ of all individuals and $68.75 \%$ of those that had palatal teeth) and four specimens of $P$. cretensis (40\%). In two individuals of the latter species, palatal teeth were present on one pterygoid but absent on the other.

There is no sexual dimorphism in number of pterygoid teeth in either of the sampled species (P. siculus: $U=36.5, \mathrm{p}=0.936 ;$ P. cretensis: $U=10, \mathrm{p}=0.667$; P. erhardii: $U=10, \mathrm{p}=1)$. Podarcis cretensis had more pterygoid teeth than $P$. erhardii $(U=3, \mathrm{p}<0.0001)$ but fewer than $P$. siculus $(U=47.5, \mathrm{p}=0.019)$. 
TABLE 1

Biometrical data of the examined lizards.

\begin{tabular}{|c|c|c|c|c|c|}
\hline Species & Specimen number & Sex & SVL [mm] & $\begin{array}{c}\text { Left pterygoid } \\
\text { [number of teeth] }\end{array}$ & $\begin{array}{l}\text { Right pterygoid } \\
\text { [number of teeth] }\end{array}$ \\
\hline P. siculus & siculus1 & $\mathrm{M}$ & 62 & 1 & 4 \\
\hline P. siculus & siculus2 & M & 58 & 2 & 2 \\
\hline P. siculus & siculus3 & M & 59 & 6 & 6 \\
\hline P. siculus & siculus4 & M & 64 & 4 & 3 \\
\hline P. siculus & siculus5 & M & 63 & 1 & 2 \\
\hline P. siculus & siculus6 & $\mathrm{F}$ & 64 & 4 & 2 \\
\hline P. siculus & siculus7 & M & 66 & 0 & 0 \\
\hline P. siculus & siculus8 & M & 70 & 3 & 3 \\
\hline P. siculus & siculus9 & M & 64 & 0 & 0 \\
\hline P. siculus & siculus 10 & M & 56 & 2 & 1 \\
\hline P. siculus & siculus11 & $\mathrm{F}$ & 58 & 4 & 2 \\
\hline P. siculus & siculus12 & M & 63 & 0 & 0 \\
\hline P. siculus & siculus13 & M & 63 & 2 & 1 \\
\hline P. siculus & siculus 14 & $\mathrm{~F}$ & 58 & 2 & 2 \\
\hline P. siculus & siculus 15 & F & 60 & 2 & 3 \\
\hline P. siculus & siculus 16 & M & 66 & 4 & 3 \\
\hline P. siculus & siculus17 & M & 65 & 7 & 7 \\
\hline P. siculus & siculus 18 & M & 59 & 3 & 4 \\
\hline P. siculus & siculus 19 & M & 59 & 0 & 1 \\
\hline P. siculus & siculus20 & $\mathrm{F}$ & 61 & $?$ & 4 \\
\hline P. siculus & siculus 21 & $\mathrm{~F}$ & 57 & 0 & 0 \\
\hline P. erhardii & erhardii1 & M & 61 & 0 & 0 \\
\hline P. erhardii & erhardii2 & M & 63 & 0 & 0 \\
\hline P. erhardii & erhardii3 & M & 59 & 0 & 0 \\
\hline P. erhardii & erhardii4 & $\mathrm{F}$ & 63 & 0 & 0 \\
\hline P. erhardii & erhardii5 & M & 58 & 0 & 0 \\
\hline P. erhardii & erhardii6 & M & 68 & 3 & 3 \\
\hline P. erhardii & erhardii7 & $\mathrm{F}$ & 52 & 0 & 0 \\
\hline P. erhardii & erhardii8 & M & 62 & 0 & 0 \\
\hline P. erhardii & erhardii9 & $\mathrm{F}$ & 57 & 0 & 0 \\
\hline P. erhardii & erhardii10 & $\mathrm{F}$ & 60 & 0 & 0 \\
\hline P. cretensis & NHMC 80.3.51.16 & M & 56 & 5 & 5 \\
\hline P. cretensis & NHMC 80.3.51.18 & M & 51 & 5 & 0 \\
\hline P. cretensis & NHMC 80.3.51.21 & M & 58 & 4 & 6 \\
\hline P. cretensis & NHMC 80.3.51.22 & M & 55 & 6 & 5 \\
\hline P. cretensis & NHMC 80.3.51.24 & $\mathrm{F}$ & 49 & 4 & 4 \\
\hline P. cretensis & NHMC 80.3.51.28 & $\mathrm{F}$ & 49 & 4 & 4 \\
\hline P. cretensis & NHMC 80.3.51.31 & $\mathrm{F}$ & 46 & 4 & 4 \\
\hline P. cretensis & NHMC 80.3.51.34 & M & 54 & 3 & 0 \\
\hline P. cretensis & NHMC 80.3.51.35 & $\mathrm{F}$ & 54 & 2 & 2 \\
\hline P. cretensis & NHMC 80.3.51.36 & $\mathrm{F}$ & 49 & 5 & 5 \\
\hline
\end{tabular}


Podarcis erhardii had fewer teeth than P. siculus $(U=31.5, \mathrm{p}=0.001)$. There is no correlation between size (SVL) and number of pterygoid teeth in P. siculus $(\mathrm{r}=0.128, \mathrm{p}=0.591)$ and $P$. cretensis $(\mathrm{r}=0.086$, $\mathrm{p}=0.813$ ). In $P$. erhardii palatal dentition was present in only one sampled specimen, so a correlation test was not performed for this species.

\section{Discussion}

Morphology and arrangement of the palatal teeth in the three species we examined are identical to those described for other lacertids (MAHLER \& KEARNEY 2006). Pterygoid teeth appear relatively late in lacertid ontogeny and occur most commonly in taxa of large size (BARAHONA \& BARBADILLO 1998). Therefore, it may be predicted that pterygoid teeth are more common in taxa (or individuals) with peramorphic skulls, as hypothesised by COSTANTINI et al. (2010). In Podarcis lizards, hypermorphosis, a subtype of peramorphosis, where the growth is extended along the same ontogenetic trajectory (REILLY et al. 1997), probably played an important role in shaping the morphological diversity of that clade, both at inter- and intraspecific levels (PIRAS et al. 2011). Podarcis siculus is one of the largest species of Podarcis, growing up to about $90 \mathrm{~mm}$ in snout-vent length but usually smaller (ARNOLD \& OVENDEN 2002). Despite that, COSTANTINI et al. (2010) found no pterygoid teeth in any of the six $P$. siculus specimens examined, yet these teeth were present in the larger Lacerta bilineata. This led the authors to speculate that the presence of palatal dentition may be a species-specific trait of L. bilineata (among sampled species, i.e., also P. siculus and P. muralis) or is a result of allometric extension of growth (COSTANTINI et al. 2010). The former hypothesis is falsified by the literature data that show that some P. siculus individuals have pterygoid teeth (KLEMMER 1957; MAHLER \& KEARNEY 2006). These authors found pterygoid dentition in 10 of $33(30.30 \%)$ and 1 of $3(33.33 \%)$ of the specimens examined, respectively. This discordance may be a result of large morphological variation of $P$. siculus (e.g., UROŠEVIĆ et al. 2012). Data from KlEMMER (1957) give some support to the latter hypothesis of COSTANTINI et al. (2010); they show that males, which have peramorphic skulls (PIRAS et al. 2011), on average have more teeth on pterygoids than do females. However, our observations on P. siculus and two species from Greece disagree with that, showing no sexual dimorphism in number of pterygoid teeth. Also, most of the specimens of $P$. siculus with no palatal dentition were not the smallest in the sample (Table 1). The specimens of $P$. erhardii were generally larger than the sampled specimens of $P$. cretensis, yet pterygoid teeth were ubiquitous in the latter and very rare in the former. Similar results were obtained by KLEMMER (1957) who found palatal dentition only in the largest male of six specimens of P. erhardii from Macedonia. Moreover, the smallest of all sampled lizards (a female P. cretensis, with SVL $=46$ $\mathrm{mm}$ ) had more pterygoid teeth than all specimens of $P$. erhardii and most of $P$. siculus. This may be surprising given the fact that $P$. cretensis from Elafonisos are hypothesised to be paedomorphic and attain smaller size than do $P$. erhardii (SKAWIŃSKI et al. 2015, in prep.). However, a similar situation is present in Acanthodactylus, which also has a paedomorphic skull (EvANs 2008) but often with palatal dentition (BARAHONA \& BARBADILlO 1997). Thus, the common presence of pterygoid teeth in P. cretensis may be a retained ancestral trait, as such teeth are also ubiquitous in P. peloponnesiacus (KLEMMER 1957; T. Skawiński, pers. obs.), probably its sister species (LYMBERAKIS et al. 2008).

It is not uncommon that younger animals attain greater size than the older ones (e.g., BoRCZYK \& PAŚKO 2011; PETERMANn et al. 2017). Thus, the immaturity of the specimens of $P$. erhardii could explain the lack of palatal dentition in all but the largest lizard. However, at least several of them exhibit skull characters that are typical for adult lacertids (BARAHONA \& BARBADILLO 1998; SKAWIŃSKI et al., in prep.). This, combined with data from KLEMMER (1957), suggests that pterygoid teeth are indeed rare in this species.

Pterygoid teeth are common in insectivorous lizards and may enhance holding and processing live prey (MONTANUCCI 1968; MAHLER \& KeARNeY 2006). Both P. cretensis and P. erhardii are mainly insectivorous but may also include carcasses (DELAUGERRE et al. 2012), eggs or fruits in their diet 
(BROCK et al. 2014). Further studies could explain whether differences in the frequency of the palatal dentition between these two species reflect differences in their diets.

Individual asymmetry in number or presence of pterygoid teeth is not uncommon in Podarcis lizards (KLEMMER 1957; see above). Such asymmetry may reflect disturbances in the Sonic hedgehog pathway, which regulates formation of palatal dentition in lizards (RICHMAN \& HANDRIGAN 2011). A common cause of the fluctuating asymmetry is anthropogenic pressure, which is a probable cause of asymmetry in the number of femoral pores, subdigital lamellae and supraciliary granules in P. muralis (LAzIĆ et al. 2013). Podarcis cretensis is threatened mainly by tourism, urbanisation and degradation of habitats (LYMBERAKIS 2009). This may be especially important in small and isolated populations with low genetic variability and heterozygosity, because in such populations deleterious mutations are more likely to be expressed (e.g., MITTON \& GRANT 1984).

Podarcis erhardii and $P$. cretensis are almost indistinguishable morphologically from each other (LYMBERAKIS et al. 2008). Our data, combined with data from KLEMMER (1957), show that pterygoid teeth are rare in P. erhardii but occur constantly in P. cretensis from Elafonisos. Although palatal dentition is not a diagnostic character for any of these forms, such strong difference in frequency (if it is representative for the whole species) supports the suggestion that these two taxa are different species (see WIENS \& PENKROT 2002).

Pterygoid teeth were used as a source of several characters in recent comprehensive morphological phylogenetic analyses of squamates, and their presence or absence seemingly diagnoses several clades (CONRAD 2008; GAUTHIER et al. 2012). However, some taxa (e.g., Helodermatidae) were scored differently in these two matrices in this respect. This probably reflects the fact that many taxa, especially rare and endangered, are scored on the basis of single or several specimens, and is a consequence of intraspecific variation of that character. Moreover, only a handful of fossil species is known from samples sufficient to give information about frequency of such a trait (e.g., TAŁANDA 2016). It was suggested that the presence of a single row of pterygoid teeth may be apomorphic to crown lacertids (EVANS et al. 2012), however, there is no intrafamilial uniformity in this respect because pterygoid teeth may be present or absent even within a single species (e.g., KLEMMER 1957; MAHLER \& KEARNEY 2006; this study). This suggests that assigning isolated lizard pterygoids (e.g., fossils) to given clades based on this putative synapomorphy may be problematic at least.

\section{Conclusions}

Pterygoid dentition shows significant variability in Podarcis lizards. All three studied species show intraspecific variation in this trait. None of the examined species exhibits sexual dimorphism in number of palatal teeth. There is also no correlation between number of teeth and lizard body size. However, palatal dentition occurs significantly more often in P. cretensis than in P. erhardii. This is the first reported anatomical trait supporting species-level divergence of these two taxa. Many individuals exhibit asymmetry in number of pterygoid teeth, which may be related to anthropogenic pressure, as in some other traits showing asymmetry. This article may be a basis for a wider study that would encompass more species and, possibly, account for any effects of geographic variability in some of the species.

\section{Acknowledgements}

We thank Petros Lymberakis (Natural History Museum of Crete, Heraklion) who generously sent us specimens of Podarcis cretensis and P. erhardii. We thank two anonymous reviewers for detailed and helpful comments on the manuscript. Corrections made by Nikki Watson (N.S.W., Australia) greatly improved the clarity of presentation. 


\section{References}

ARNOLD E.N. (1973). Relationships of the Palaearctic lizards assigned to the genera Lacerta, Algyroides and Psammodromus (Reptilia: Lacertidae). Bulletin of the British Museum of Natural History, Zoology 25: $289-366$.

ARNOLD E.N. (1989). Towards a phylogeny and biogeography of the Lacertidae: relationships within an Old-World family of lizards derived from morphology. Bulletin of the British Museum of Natural History, Zoology 55: 209-257.

ARnold E.N., ArRibas O. \& CARRAnZA S. (2007). Systematics of the Palaearctic and Oriental lizard tribe Lacertini (Squamata: Lacertidae: Lacertinae), with descriptions of eight new genera. Zootaxa 1430: $1-86$.

ARnold E.N. \& Ovenden D. (2002). A Field Guide to the Reptiles and Amphibians of Britain and Europe. 2nd edition, Harper Collins Publishers, London.

BARAHONA F. \& BARBADILLO L.J. (1997). Identification of some Iberian lacertids using skull characters. Revista Española de Herpetologia 11: 47-62.

BARAHONA F. \& BARBADILLO L.J. (1998). Inter- and intraspecific variation in the post-natal skull of some lacertid lizards. Journal of Zoology 245: 393-405. https://doi.org/10.1111/j.1469-7998.1998. tb00114.x

BELL C.J. \& MEAD J.I. (2014). Not enough skeletons in the closet: collections-based anatomical research in an age of conservation conscience. Anatomical Record 297:344-348. https://doi.org/10.1002/ar.22852

BORCZYK B. \& PAŚKO Ł. (2011). How precise are size-based age estimations in the sand lizard (Lacerta agilis)? Zoologica Poloniae 56: 11-17. https://doi.org/10.2478/v10049-011-0004-8

Brock K.M., Donihue C. \& PAfilis P. (2014). New records of frugivory and ovophagy in Podarcis (Lacertidae) lizards from East Mediterranean Islands. North-Western Journal of Zoology 10: 223-225.

CONRAD J.L. (2008). Phylogeny and systematics of Squamata (Reptilia) based on morphology. Bulletin of the American Museum of Natural History 310: 1-182. https://doi.org/10.1206/310.1

Costantini D., Alonso M.L., Moazen M. \& Bruner E. (2010). The relationship between cephalic scales and bones in lizards: a preliminary microtomographic survey of three lacertid species. Anatomical Record 293: 183-194. https://doi.org/10.1002/ar.21048

Delaugerre M., Grita F., Lo Cascio P. \& Ouni R. (2012). Lizards and Eleonora's Falcon (Falco eleonorae Gené, 1839), a Mediterranean micro-insular commensalism. Biodiversity Journal 3: 3-12.

Evans S.E. (2008). The skull of lizards and tuatara. In: GANS C., GAUNT A. \& AdLER K. (eds) Biology of the Reptilia. Volume 20. Morphology H. Society for the Study of Amphibians and Reptiles, Ithaca, NY: $1-347$.

Evans S.E., Jones M.E.H. \& Matsumoto R. (2012). A new lizard skull from the Purbeck Limestone Group (Lower Cretaceous) of England. Bulletin de la Société géologique de France 183: 517-524. https://doi.org/10.2113/gssgfbull.183.6.517

Gauthier J.A., Kearney M., Maisano J.A., Rieppel O. \& Behlke A.D.B. (2012). Assembling the squamate tree of life: perspectives from the phenotype and the fossil record. Bulletin of the Peabody Museum of Natural History 53: 3-308. https://doi.org/10.3374/014.053.0101

KLEMMER K. (1957). Untersuchungen zur Osteologie und Taxionomie der europäischen Mauereidechsen. Abhandlungen der Senckenbergischen naturforschenden Gesellschaft 496: 1-56.

Lazić M.M., Kaliontzopoulou A., CARretero M.A. \& Crnobrnja-Isailović J. (2013). Lizards from urban areas are more asymmetric: using fluctuating asymmetry to evaluate environmental disturbance. PLOS ONE 8: e84190. https://doi.org/10.1371/journal.pone.0084190 
LYMBERAKIS P. (2009). Podarcis cretensis. The IUCN Red List of Threatened Species 2009. Red List Unit, Cambridge: e.T157252A5060934. https://doi.org/10.2305/IUCN.UK.2009.RLTS.T157252A5060934.en

Lymberakis P., Poulakakis N., Kaliontzopoulou A., Valakos E. \& Mylonas M. (2008). Two new species of Podarcis (Squamata; Lacertidae) from Greece. Systematics and Biodiversity 6: 307-318. https://doi.org/10.1017/S1477200008002727

MAHLER D.L. \& KEARNEY M. (2006). The palatal dentition in squamate reptiles: morphology, development, attachment, and replacement. Fieldiana, Zoology 108: 1-61. https://doi.org/10.3158/00150754(2006)108[1:TPDISR]2.0.CO;2

MitTON J.B. \& GRANT M.C. (1984). Associations among protein heterozygosity, growth rate, and developmental homeostasis. Annual Review of Ecology and Systematics 15: 479-499. https://doi.org/10.1146/annurev.es.15.110184.002403

MONTANUCCI R.R. (1968). Comparative dentition in four iguanid lizards. Herpetologica 24: 305-315.

Petermann H., Mongiardino Koch N. \& Gauthier J.A. (2017). Osteohistology and sequence of suture fusion reveal complex environmentally influenced growth in the teiid lizard Aspidoscelis tigris - Implications for fossil squamates. Palaeogeography, Palaeoclimatology, Palaeoecology 475: 12-22. https://doi.org/10.1016/j.palaeo.2017.02.034

Piras P., Salvi D., Ferrara G., Maiorino L., Delfino M., Pedde L. \& Kotsakis T. (2011). The role of post-natal ontogeny in the evolution of phenotypic diversity in Podarcis lizards. Journal of Evolutionary Biology 24: 2705-2720. https://doi.org/10.1111/j.1420-9101.2011.02396.x

ReILly S.M., WiLEY E.O. \& MEINHARDT D.J. (1997). An integrative approach to heterochrony: the distinction between interspecific and intraspecific phenomena. Biological Journal of the Linnean Society 60: 119-143. https://doi.org/10.1111/j.1095-8312.1997.tb01487.x

RichMAN J.M. \& HANDRIGAN G.R. (2011). Reptilian tooth development. Genesis - The Journal of Genetics and Development 49: 247-260. https://doi.org/10.1002/dvg.20721

SKAWIŃSKI T., BORCZYK B. \& TURNIAK E. (2015). Heterochrony in the evolution of Podarcis lizards (Lacertidae): insights from cranial osteology. In: BORCZYK B., OGIELSKA M., KolendA K. \& SKAWIŃSKI T. (eds) Programme and Abstracts, SEH 18th European Congress of Herpetology, 7-12 September 2015, Wrocław: 180. University of Wrocław, Poland.

TaŁANDA M. (2016). Cretaceous roots of the amphisbaenian lizards. Zoologica Scripta 45: 1-8. https://doi.org/10.1111/zsc. 12138

URoŠEviĆ A., LJUBiSAVLJEVIĆ K., JeliĆ D. \& IVANOVIĆ A. (2012). Variation in the cranium shape of wall lizards (Podarcis spp.): effects of phylogenetic constraints, allometric constraints and ecology. Zoology 115: 207-216. https://doi.org/10.1016/j.zool.2012.01.003

WIENS J.J. \& PENKROT T.A. (2002). Delimiting species using DNA and morphological variation and discordant species limits in spiny lizards (Sceloporus). Systematic Biology 51: 69-91. https://doi.org/10.1080/106351502753475880

Manuscript received: 12 October 2016

Manuscript accepted: 28 June 2017

Published on: 19 October 2017

Branch editor: Dominique Adriaens 